\title{
Smoking Cessation Among Methadone Users In Mauritius
}

\author{
Gilbert Roland \\ $R N$, Bsc(Hons), MPH. \\ $M O H \& Q L M A U R I T I U S$ \\ GROLAND642@GMAIL.COM
}

\begin{abstract}
Background: This study aims to evaluate the aspects of smoking cessation in Mauritian users of methadone. A large number of researchers have suggested examining smoking in this population, as high rate of tobacco use has been reported in this population. With regards to the interventions for smoking cessation, very few are formulated to be used in the treatment of methadone.
\end{abstract}

Method: At the stages of Transtheortical model, methadone users are surveyed in a cross sectional study using the Global Adult Tobacco Survey instrument. Data was collected from two groups and compared. One group was treated with the standards protocol of therapy while other with interventions sessions of motivational enhancement therapy. Both inferential and descriptive statistics encompassing non-parametric tests were used to analyze the collected data.

Results: At the baseline for survey, the results demonstrated mean of 9.7 with a standard deviation of 5.8 self reported cigarettes per day. Out of which $56 \%$ were in state of precontemplation. Literacy levels were generally low in the whole community. At post intervention, patients reported decreasing their smoking by an average of $2 \%$. Till the session of follow-up, $41 \%$ participants of the final sample self-reported a 50\% decline in smoking while $26 \%$ reported no change. Generally, no major differences were observed between the groups concerning education, methadone intake doses, employment, marital status or age.

Conclusion: Motivational enhancement therapy that serves as a catalyst for stage movement as well as a barrier for stage regression.

Keywords: Motivational Enhancement Therapy, Methadone Users, Smoking Cessation, Transtheoretical Model Stages of Change

\section{Introduction}

It is an indubitable fact that the world has a scientific reason to control the injurious causes of tobacco to health that continuously lead to death and disability, since usage of tobacco remains a serious and a major public health issue (CDC, 2013). According to ITC Project (2012), it has been predicted that continuous smoking will be responsible for killing almost ten million people by the year end 2070. Moreover, it contributes to up to $70 \%$ for the death causes among people in the world where mostly the populations belongs to the developing countries. The same project also highlighted the same issue in Mauritius. Estimates show that more than 1.3 billion people consume tobacco as smoking around the world. The Mauritian republic is facing the issues of drugs related consequences (People, 2011). Thousands Mauritians are consuming methadone for addiction relieving purposes. Its consumption is causing increase in health related issues.

\section{Background Information}

Smoking is the most preventable explanation for passing and woe worldwide (ITC Project, 2012). The detail given by the Ministry of Health uncover that more than a thousand Mauritians are casualties of tobacco every year (Buglow, 2013). Despite the fact that smoking rates have not increased in the course of recent decades, recent assessment infer that $20 \%$ of Mauritius individuals smoke. There is a wide mixed bag of intercessions intended to diminish tobacco use (ITC Project, 2012). From the worldwide viewpoint, tobacco remains the heading explanation for unexpected passing, which brought about hundred million individuals, having lost their lives in the twentieth century and is anticipated to kill one billion individuals worldwide in the 21 st century. Around the substance clients, methadone identified therapy is an alternate noteworthy route for reducing demise (Shiffman, 2010:382). Expansion in the passing rates arises because of substance abuse related harming among people. Over $90 \%$ of individuals in inpatient treatment for alcohol dependence have been found to smoke cigarettes (Sung et al., 2011:40), and rates ranging from $74 \%$ to $88 \%$ have been reported for individuals in treatment for drug dependence (Louden \& Skeem, 2011, p.1-9).

Amongst methadone maintained individuals (MMT), a high smoking prevalence rates have been reported (Stein et al., 2013:486). Methadone has been a medication used for more than the past 40 years in the treatment of heroin addiction. It acts by occupying the opiate receptor and blocking the "high" that comes from heroin use. Methadone also eliminates withdrawal symptoms and craving for heroin. Tobacco executes and each 
cigarette lessens the life of a smoker by seven minutes (WHO, 2013). The World Health Organization and Tobacco Free Initiative estimated that with the current pattern, more than eight million people will die from tobacco use by 2030 (WHO 2013). According to the patterns, trends of alcohol, and other drug use series for Mauritius the population of Mauritian methadone users has gone up dramatically. Since 2010, the number of methadone users has been increased to 6000 per day in our island exhibiting $200 \%$ increase in duration of just three years (Dunn et al., 2010:1). Opioid medicine centres might grow to perfect settings to improve and execute smoking suspension mediation (Stotts et al., 2010:1727). In this regard, numerous patients can become stable at first place and accomplish delayed times of forbearance from unlawful medication utilization. This intervention will give them great confidence to quit smoking. Second, patients can regularly go to the facility on a normal groundwork (for instance, the methadone obsession).in facility, they remain occupied with medication for augmented periods, which can provide a chance to screen their smoking status. Third, numerous centres follow the standards for smoking cessation based on state and elected regulations. This recommends that an effective mediation in the connection of one facility may sum up well to different facilities with better useful techniques. Fourth, information proposes that medicine programs supporting smoking discontinuance can affect probability of smoking cessation.

\section{Statement Of The Research Problem}

Given the high rates of tobacco use in methadone-maintained individuals, numerous authors have suggested that more research is required to address smoking in this population (Haynes and Smith 2013:1). Despite this, relatively few smoking interventions have been designed for those in methadone treatment (Brown et al., 2012:37). In order to fill this gap, this study examines factors associated with smoking cessation in the methadone users using an adapted version of the Global Adult Tobacco Survey (GATS, 2014). This is validated into the native Creole language. The high rate of smoking prevalence, coupled with the daily dispensing of methadone presented a unique opportunity for implementing an innovative smoking cessation programs with methadone-dependent individuals in treatment here.

\section{Purpose Of The Study}

The main purpose of this research was to examine and investigate whether current commissioned health practices (in Mauritius) are appropriate for smoking cessation for this community. The findings will enable the academia as well as the policy makers to direct their efforts towards a higher level of evidence based and effective health interventions, particularly towards promoting empowerment.

\section{Objectives}

This study aims at empowering victims towards smoking cessation and it is expected to be achieved through the following strategies:

- By assessing smokers, intention to quit smoking using the Transtheoretical model

- By determining their level of dependence on tobacco

- By identifying the barriers to quit smoking and suggest viable recommendations

\section{Definitions Of Keywords/Concepts}

Methadone Users: Individuals using methadone medicine for addiction

Motivational Enhancement Therapy: It is described as a therapy to help the patients or clients to make their beliefs and perceptions clear for taking any decision. This treatment pattern frequently used to treat the addictions encompassing the substance abuse, as well as alcohol abuse. Significantly, it aids to empower the addicted person with the enhanced capability of self control. The sessions focused on motivational variables, personal feedback, behavioral change plans, and self-efficacy, for the purpose like to quit smoking.

Smoking Cessation: Smoking cessation is the procedure to quit smoking among the tobacco users.

Transtheoretical Model Stages of Change: The Transtheoretical health behaviour change model is a product of an analysis of leading psychotherapy and behaviour change model. It is one of the most innovative ideas in the area of promoting health and prevention of disease, the possibilities for planning and implements interventions based on the specific characteristics of populations or groups.

\section{Research Methodology}

The research was conducted in two phases. In first phase, cross sectional survey was conducted while in phase two randomised control trial was performed to compare two groups. There are two broad categories of research in terms of approach employed to reach conclusions: inductive and deductive (Babb, 2013). The approach chosen in this research is inductive. Hence, specific information at specific time is processed to reach 
the general conclusion. It is a three-step method, (1) methodical examination of the phenomenon underinvestigation, (2) recognition of pattern or themes in the observation, and (3) development of the theory with the help of the observed pattern or theme (Babb, 2013). It is also known as a bottom-up approach which is presented as follows:

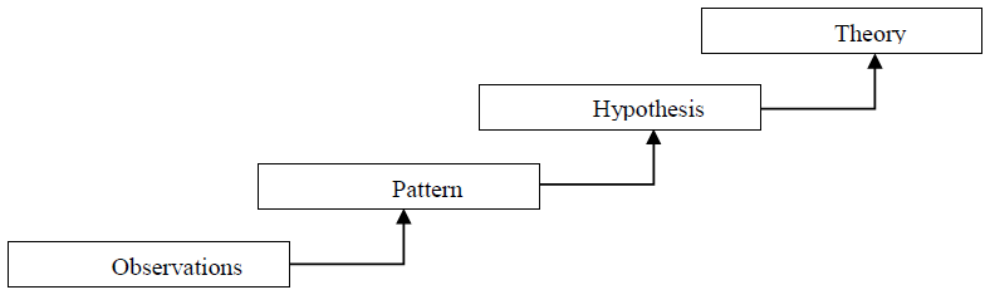

Figure 1: Bottom up approach of research (Babb, 2013)

\section{Phase One}

This is a quantitative, set in the positivistic paradigm (Killam, 2013:32). Data required for phase one was cross-sectional. All the data was of primary nature collected through questionnaire survey. Systems approach framework was applied in the collection of data.

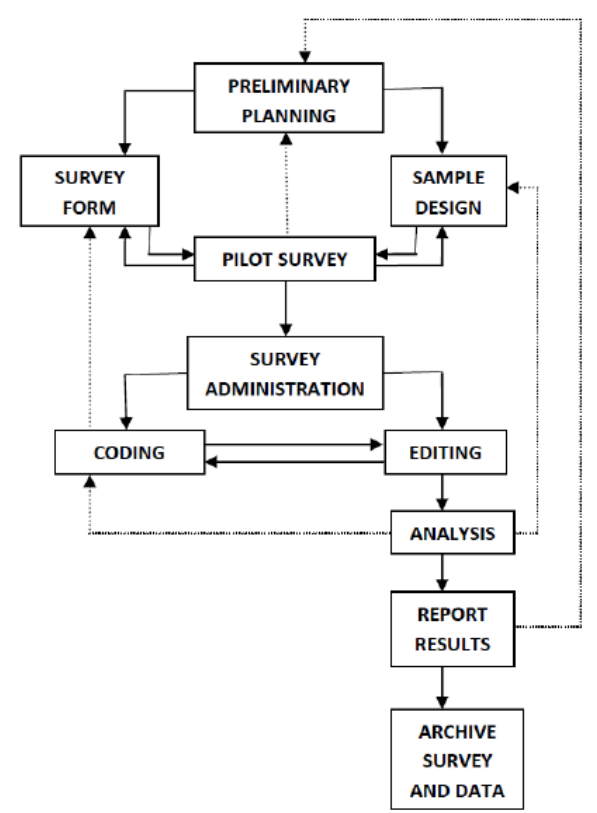

Figure 2: System Approach (Mämmelä, 2007)

This is an integrated and comprehensive methodology for data collection which follows a procedure of interconnected and logical steps towards the final outcome (Bendassolli 2013:50). This study was an endeavour to provide a true picture of the actual population of methadone users in Mauritius through sampling at each of the five regional hospitals. For recruitment of participants and data collection, an information sheet and recruitment advert was placed at the clinics so that interested persons could express their participation interests. Conversely, participants were selected randomly. Targeted population of this study was the methadone users and the total number of methadone registered methadone users in Mauritius was 6000 (Finette, 2013:89; PATAODU, 2010). The size of the representative sample in this study was 400 in which each person had to fill the questionnaire. This size was selected via using Israel (2013) sample size calculation formula (Israel). Noncompliant methadone users, those with disease condition that may affect the validity of their response, e.g. suffering from depression, psychiatric illnesses, are excluded from the study. Only registered methadone users for at least six months on the therapy were considered eligible for this research. The setting of this research was a quiet room at the same hospital where the participating individuals had received the methadone. Participants were also allowed take the questionnaire home and return it to the researcher in a self-addressed prepaid sealed envelope by post. Those that participated in the pilot study were not included in the main study to avoid bias (Winfree et al., 2013:274). All voluntary participating individuals were provided with the consents forms. These consent forms were kept in a personal separate suitcase under lock and only the researcher has the key to access the forms. In order to maintain the confidentiality of the participants, the actual questionnaires only contained an index number and no personal information. 
The Global Adult Tobacco Survey Tool and the Fagerström Nicotine Dependence Score were used to collect information from participants. The ten-page questionnaire, consisting of eight sections to gather information about smoking cessation, mental health and primary health care was given to the participants of Mauritius. Most of the items in the developed questionnaire were close-ended questions and require the participants to respond using a five-point Likert scale response format. Some of the items required the respondents to fill in the blanks with an appropriate response. The rest of questions were in checklist formats including an "other" option in which respondents could check all that applied. Data collection was done over a twelve consecutive days period, the researcher being physical present at each of the regional hospital three whole days from morning to afternoon.

\section{Phase Two}

The second phase of research started after the initial questionnaire distribution phase. In this phase, the researcher randomly recruited the participants and divided them into two groups: Counselling Add-on Intervention group and Standard Care group. Psychological counselling was offered to first group of participants and made them to attend psychologist motivational enhancement therapy clinics once a week as compared to another group only having the standard care that is the methadone maintenance doses only. 150 participants were randomly selected for each arm of the study using following illustration.

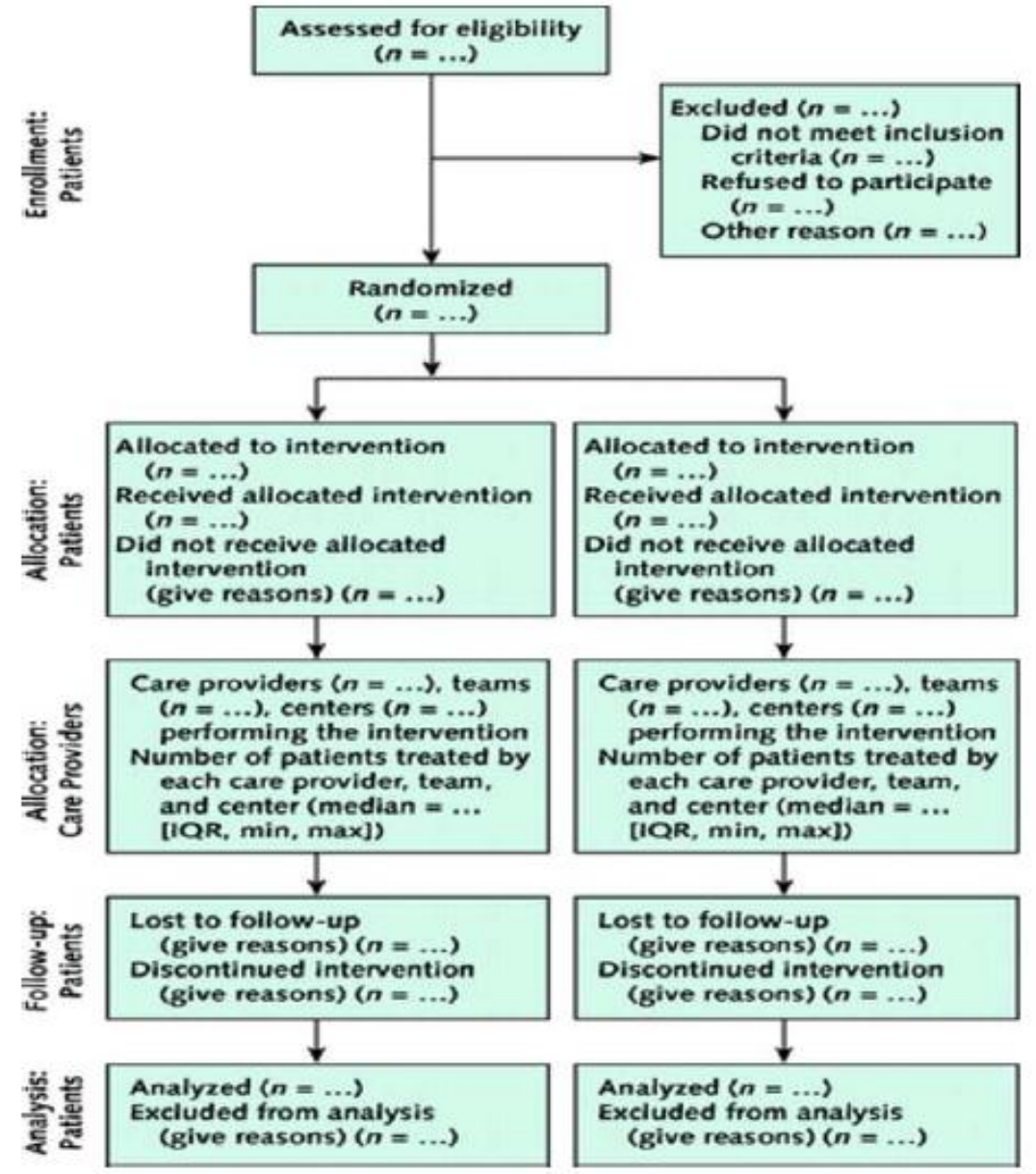

Figure 3: RCT Flow Chart Diagram

\section{Analysis}

Data analysis was performed using STATA, a statistical software package appropriate to be used in social sciences (Acock, 2012). The appropriate descriptive statistics such as means, standard deviations, proportions and percentages were used to describe the findings of the study. Chi-square statistics to compare variances and T-test statistics to compare means were also used for testing any significant differences in smoking cessation. Internal consistency reliability of the subscales of the instrument was determined by calculating a series of Cronbach's alphas (Anil, 2012:89). The stability reliability of the instrument was tested by test retest method on a small convenience sample of ten participants that were excluded from the main sample of the current study. The stability reliability coefficient for the Stage of Change subscale and for the 
efficacy expectations subscale is 1.0 and 0.51 respectively. The overall stability reliability coefficient for the instrument was 0.71. Cronbach's alpha, the subscales of the instrument had internal consistency coefficients, range from 0.78 for the 4 Rs (reluctance, rebellion, resignation and retaliation) subscale to 0.88 for the outcome expectations subscale.

A total of 265 participants (men and women) had returned the forms from phase one. Scrutinizing the filled questionnaires, 37 questionnaires were disqualified for the following reasons:

\begin{tabular}{lc}
\hline $\begin{array}{l}\text { Number of invalid } \\
\text { questionnaires }\end{array}$ & Reasons \\
\hline 7 & discharge from the unit for non-compliance issues \\
\hline 23 & $\begin{array}{c}\text { reported irregular treatment and non-daily compliance as } \\
\text { follows discharged against medical advice }\end{array}$ \\
\hline 1 & falsifier data detected in form non-methadone user status \\
\hline 6 & severe psychiatric impairment \\
\hline & Table 1: Invalidated Questionnaires
\end{tabular}

Average age of the participants in the study is 38.7 years with standard deviation 4.8 . Only $4 \%$ of the participants were educated above the high school. Average time for which participants are smoking was 12 years with standard deviation of 6.2 while average number of cigarettes smoked per year was 13.4 with standard deviation 7.6. Their mean score of nicotine measure using the built-in Fagerstrom Tolerance Questionnaire ranging from $0-11$, is 7.0 with standard deviation 1.8 , indicating high nicotine dependence $(\mathrm{M}=\mathrm{mean}, \mathrm{SD}=$ standard deviation)

\begin{tabular}{lll}
\hline Measures & M & SD \\
Cigarettes per day (\#) & 13.4 & 7.6 \\
Age first smoked (years) & 13.7 & 3.5 \\
Age smoked regularly (years) & 16.3 & 1.4 \\
Fangerstrom TQ score (0 - 11) & 7.0 & 1.8 \\
Tolerances DS (0 - 10) & 7.2 & 2.3 \\
\hline
\end{tabular}

Table 2: Smoking Characteristics at Baseline

Stages membership for quitting smoking was 56\% $(\mathrm{n}=148)$ pre-contemplation, $38 \%(\mathrm{n}=101)$ contemplation, and $6 \%(\mathrm{n}=16)$ preparation. Due to the low numbers of participants in preparation, contemplation and preparation stages were combined to produce a contemplation-preparation MET vs. SC group comparison for phase two. The mean number of self-reported cigarettes per day at baseline for the final sample was 9.7 with SD 5.8. The average self-reported cigarettes per day for participants initially was 11.4 (SD = 7.6). On average, patients reported decreasing their smoking by an average of $6.2(\mathrm{SD}=11.3)$ cigarettes per day during the study window. There were no participants who self-reported quitting smoking during the study and biological measures was not performed to confirm smoking abstinence. From baseline to follow-up, fortyone percent participants of the final sample self-reported a 50\% decrease in smoking while twenty-six percent of the participants reported an increase in smoking.

Result of the comparison in the following table shows that there were no differences between the groups on age, marital status, employment or education. Further no significant differences found between the groups on education and employment. Number of women in the MET group was 17 while in the SC group, it was 14. Also, mean education in MET is 10.2 years while that in the SC group is 11.3 years. Difference between stage of change, nicotine dependence, and smoking quantity at baseline was not different between the two groups. Mean value of self-reported number of cigarettes smoked per day in MET group was 9.7, which was significantly higher than that of 11.3 in the SC group. Nonetheless, the difference between quantity, frequency, and severity of drug abuse between the two groups was not significant. The difference of alcohol diagnosis in the past month between MET and SC was significant such that in SC, there are 7 participants with an alcohol abuse diagnosis which there was no such participant in the MET group. There were no differences between groups on any measures of psychiatric co-morbidity. 


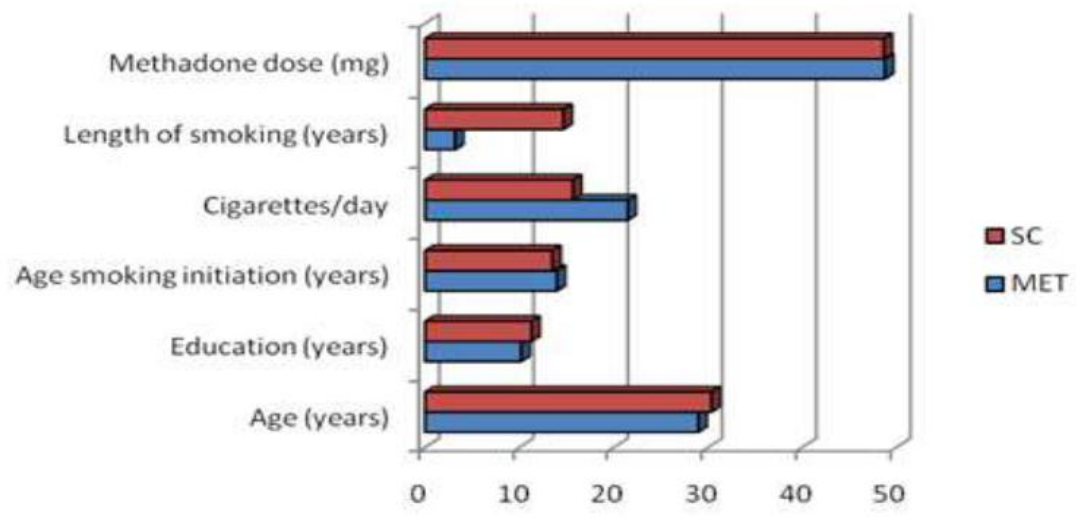

Figure 4: Values for different variables in two groups

Chi-Square Tests were used to test relation ship between two groups namely MET Vs SC; and oneway ANOVA was used to illustrate difference of self-reported smoking reduction between the two groups. Chisquare analysis indicated no group differences on self-reported smoking reduction. The chi-square analysis also showed no difference between MET vs. SC on the dichotomous measure of self-reported smoking increase. Results from the one-way ANOVA did not find a significant difference between MET and SC on self-reported cigarettes per day at follow-up, after co-varying baseline values.

\begin{tabular}{|c|c|c|c|c|c|}
\hline & $\begin{array}{c}\text { Sum of } \\
\text { Squares }\end{array}$ & df & $\begin{array}{c}\text { Mean } \\
\text { Square }\end{array}$ & F & Sig. \\
\hline Between & 0.131 & 1 & 0.159 & 1.8 & 0.201 \\
Groups & 6.122 & 264 & 0.089 & & \\
Within Groups & 6.325 & 265 & & \\
Total &
\end{tabular}

Table 3: ANOVA

\begin{tabular}{|l|l|l|l|}
\hline & Value & df & $\begin{array}{c}\text { Asymp. Sig. } \\
\text { (2-sided) }\end{array}$ \\
\hline Pearson Chi-Square & $52.000^{\mathrm{a}}$ & 264 & 0.332 \\
Likelihood Ratio & 56.194 & 264 & 0.017 \\
Linear-by-Linear Association & 3.171 & 1 & 0.161 \\
No of Valid Cases & 265 & & \\
\hline
\end{tabular}

Table 4: Chi-Square Tests

\section{Discussion Of Research Results}

Findings indicated that MET did not produce extensive differential rates of smoking cessation or reduction among the sample compared to standard care. In fact, none of the participants in the study quitted fully smoking and few demonstrated reduction at only five-week follow-up (2-4\%). Although the intervention was tailored to the stage of change for smoking and administered carefully, it was not potent enough to combat all barriers to quitting smoking identified among this group. In traditional settings, Motivational Enhancement Therapy as an individual therapy, has been proved as practical (Lundah and Burke, 2009:1232). In this study, the following components of an MET are found to be significantly effective.

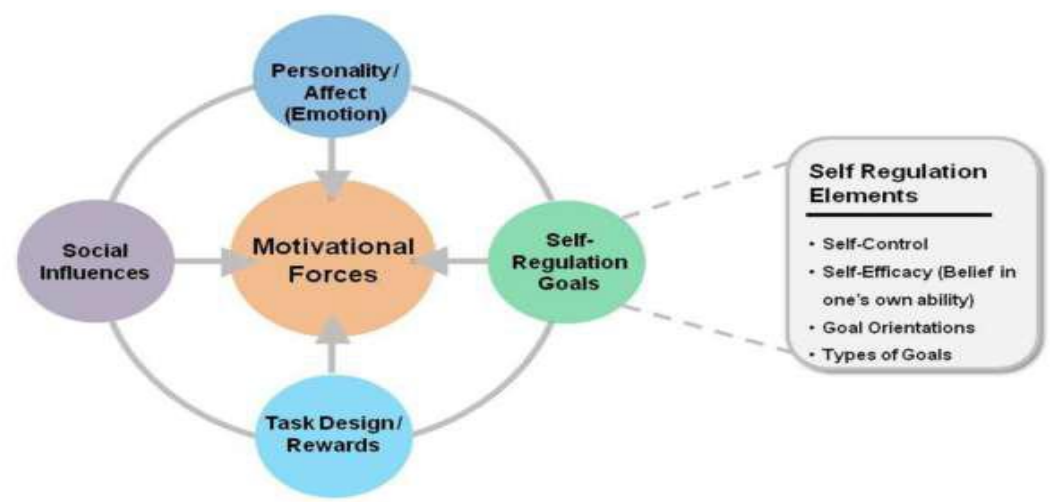

Figure 5: Motivational Enhancement Therapy - Regulations 
The importance of quitting smoking was not assessed, nevertheless, it can be speculated that smoking cessation was a low priority on their laundry list of changes to be accomplished. The "four R's": reluctance, rebellion, resignation, and rationalization were not objectively assessed. Motivational strategies may be more efficacious with pre-contemplators when these are considered and targeted appropriately, by change hinged on building motivation (Baker et al., 2011:2). It is likely that therapists underestimated ambivalence, misjudged pre-contemplative reasoning, and were unable to elicit commitment for change based on the lack of significant quitting or quit attempts (Caplan et al., 2011:238). Montgomery et al. (2011:357) support the effectiveness of MET in reducing the smoking rate in the population of African American. They conducted the study via taking a design of randomized control trial. In this study, they compared the efficiency of MET with the intervention of counsel as usual (CAU) in 194 outpatients who were African American adults and looking for substance abuse treatment. The results of the study exhibited, in the first twelve weeks of the research, the enhanced rate of retention among females with MET compared to CAU.

Concerning the case of males, no difference was found between the groups with the interventions of MET and CAU. Alternatively, Montgomery et al (2011:360) also found the increased rate of self reporting regarding drug using days in one week, in MET participants compared to the participants CAU. In this way, these studies assure that motivational strategies are more efficacious with pre-contemplators when these are considered and targeted appropriately, by change hinged on building motivation.

\section{MET Considerations}

The application of MET and Motivational Intervention (MI) to smoking cessation and reduction should be considered in the context of its original use as a treatment for addiction problems (Barnett et al, 2012:1325). There are several studies that have approved the positive effects of these interventions of MI and MET concerning different group of people encompassing adults, adolescents, and women. In this regard, Heckman et al. (2010:410) conducted the meta- analysis and a systematic review via considering 31 research articles. They examined the efficacy of motivation interviewing as an intervention for cessation of smoking and recognized the relation of the observed effects of the treatment. The result of the study showed the great probability of abstinence among the adults, pregnant women (Eades et al., 2012:42), adolescents, as well as in the individuals with mental or physical sickness.

\section{Implications for Intervention}

Kong, Singh and Krishnan-Sarin (2012:1394), suggested that smoking prevention and cessation efforts incorporate culturally appropriate strategies for minority groups. For African-Americans in particular, tailored treatment should focus on smoking as an issue for the entire family. Many participants in the present study reported living with parents or other family members (44\%) and over one-third (37\%) were living with their partner and/or children upon admission to treatment. Seventy-one percent of them reported living with another smoker. Employing a family systems strategy would also address partner, household, and environmental smoking, common barriers to quitting among Mauritian smokers in general. Special prevention efforts targeting the children of smokers with co-factors may be critical for interrupting the growing concentration of smoking in psychiatric patients and lower socioeconomic groups. The heritability index of smoking and genetic contributions to smoking initiation (Belsky et al 2013:534), (and failure to quit) should be considered in conceptualizing prevention and treatment of nicotine dependence. Routine screening for depression and other psychiatric co-morbidity in female smokers is critical and mood management may be indicated. Screening for depression and in conjunction with methadone treatment is complicated by the overlap in symptomatology (Moore, 2011:2701; Hung et al., 2011:592).

Consideration of common characteristics and assessment of actual depressive features requires skilled clinicians and specialized screening tools. Results from both observational and experimental studies indicate that reduction of smoking behaviour can have significant health benefits (Mozaffarian et al., 2012:1514). The findings of the present study have important implications for the design of tobacco interventions. Risk reduction strategies may be indicated for substance-abusing enrolled in drug treatment who have invariably failed to quit smoking, who would like to quit but are unable, and/or those who do not want to quit but prefer to reduce smoking. A prior study of methadone maintained behaviours showed that the vast majority reported preference for nicotine replacement products (Storey et al., $2011 \mathrm{p} 8$ ). Nicotine medications may also enhance reduced smoking, especially among highly dependent and less motivated smokers (Sofuoglu et al., 2012:413). NRT effectively reduces the severity of nicotine withdrawal and nearly promotes long-term cessation rates compared with placebo or psychotherapy alone (Douaihya et al., 2013:264). Individuals who receive methadone treatment for heroin addiction generally experience less craving for opiates and few withdrawal symptoms. Behavioural reinforcement and learning achieved in methadone treatment should be applied to smoking and transferred to nicotine replacement. 


\section{Stages of Change}

The present study had the strength of assessing motivation to quit using the transtheoretical model. The stage of change paradigm accurately captures low motivation levels among the sample and helps explain absence of behaviour change. As mentioned previously, it is unknown whether the pre-contemplators in this study were reluctant, rebelling, resigned, rationalizing, or some combination. Furthermore, approximately half the sample was in pre-contemplation at 5-week check-up (47\%) with poor differences between MET and SC on stage distribution. For methadone-maintained smokers being treated for both substance abuse and nicotine dependence, it is probable that drug abstinence takes precedence along with management of various psychosocial, medical, family, legal, and psychiatric concerns (Jiloha, 2012:64). Since tobacco use is legal and socially acceptable in a drug treatment setting, immediate priority for modification of this health risk behaviour remains low (Edwards et al., 2011:580). Collins et al. (2012:931) interviewed the alcohol users for two years regularly. They also measured the 'Motivation to Change' and attendance for treatment via SOCRATES and Addiction Severity Index. They evaluated the parameters like alcohol dependence, problems, and quantity among the participants over the period of two years. The outcomes of the study illustrated that the significance of motivation for change may prevail over attendance for treatment to support in the considered population concerning the behaviour change regarding alcohol use. MET seems to have succeeded in its objective to move individuals along the stage continuum, raise awareness about smoking, and ultimately move substance or alcohol users towards taking positive action in the future to cease the habit (Collins et al., 2012:931).

\section{Processes of Change}

Typically, smokers who spontaneously quit smoking do not seem to engage in coping activities typically associated with their stage of change (Campbell et al., 2013:1562). For instance, smokers in action have reported less experiential process activity. One explanation for this anomalous pattern is external motivation and imposed change, which is distinct from the Transtheoretical Model's intentional behaviour change construct. One explanation for this anomalous pattern is external motivation and imposed change, which is distinct from the Transtheoretical Model's intentional behaviour change construct.

Little was unveiled about the process activity of smoker's in pre-contemplation and contemplation stages for quitting smoking. From the broader literature on processes of change, it appears that few coping strategies are employed by individuals with low intention to quit smoking. In this regard, five stages of change are essential to consider. According to Eslami et al. (2102), for the smokers in precontemplation stage, the predictable outlines about the association between stages of changes and decisional balance are the destructive effects of smoking, but of decline significance compared to the benefits of smoking. However, at the stage of contemplation, the advantages and disadvantages intersect, and ultimately, compared to the advantages in the further stages of change, the cons have a greater importance. This study concludes that the motivation and temptation assists to decline the nicotine dependency, decrease in pros and increase in cons (Eslami et al., 2012:1). Self re-evaluation involves emotional and cognitive reappraisal of one's values in respect to the problem behaviour, specifically, cigarette smoking. Stress and confusion can arise when one's values are in conflict with dominant societal values. Smoking is generally viewed by society as an unacceptable behaviour because foetal health is compromised. An interventionist may be able to elicit motivation for change by bringing to light the inconsistency between smoking behaviour and self-perception as a responsible and caring mother. Self re-evaluation might involve thinking about oneself as a non-smoker and imagining the experience of positive feelings from non-smoking.

\section{Conclusion}

The present study had the strength of assessing motivation to quit smoking using the transtheoretical model. The stage of change paradigm accurately captures low motivation levels among the sample and helps explain absence of behaviour change. Focused smoking intervention requires scaling up by medical, obstetrical and nurses teams, and revision of reimbursement policies for nicotine treatment deserves scientific and public health attention. Although drug abstinence has traditionally taken precedence over smoking, it has been suggested that cigarette smoking may actually be worse for the developing foetus than use of alcohol.

\section{Recommendations}

Psycho education of interventionists and patients alike may be a first step in changing the medical and drug treatment milieus. It is evident that methadone-maintained smokers represent an underserved, disadvantaged group with multiple and complex issues surrounding their lives, only one of which is the inability to quit cigarette smoking. Whereby the absolute recommended necessity to review and update current practitioner policy. The Mauritius government, as well as the health care organization must modify the treatment protocol for such patient via developing the standards regarding behavioural therapy of the methadone users and other substance abusers. The further studies concerning the people from different background and ethnicity is 
essential for the sake of the lives of individuals in methadone maintenance treatment. These researches must focus on the viable treatment options and smoking behaviours. Along with this, the physicians can also play a better role. The health care professionals can actively provide treatments on the basis of pharmacologicallybased smoking cessation approaches to their. Such interventions facilitate the alleviation of possible adverse effects occurred due to cessation of smoking. For the nicotine dependent patients, the development of improved, modified or adequate interventions with psychotherapeutic or psycho-social, and motivation-enhancing curriculums to maintain treatment are imperative. These approaches can assist to elucidate the significance and specificity of current interventions concerning the greater potential to cease smoking compared to one which is presently attained in the patients of Mauritius.

\section{Limitations Of The Study}

This study also possesses certain limitations. One of the potential content weaknesses of the MET intervention employed in the present study is lack of emphasis placed on the importance of changing smoking behaviour in extremely limited time. Although the sessions focused on motivational variables, personal feedback, behavioural change plans, and self-efficacy, the perceived importance of quitting smoking may have been relegated. For better results, the researchers must spend more time to gather pertinent data. As it is known that smoking involves a complex web of personal and social factors and in order for MET to be successful, patient goals should be realistic and built on their resources for change. Given the very limited time for change of the participants in the current study, MET may have not been the optimal intervention strategy. Conversely, the final sample size of the study was 265 , which was smaller than the projected size of 400 . Due to this difference in the projected and final sample size, the statistical power of this study to detecting differences between groups was weak.

\section{Acknowledgements}

I thanked to God, my supervisors, participants and supporters who assist me during the entire research.

\section{References}

[1]. Acock, A. C., (2012), A Gentle Introduction to Stata, Revised Third Edition Book [Paperback] Alan C. Acock (Author), STATA Corp USA, Retrieved from http://www.stata.com/bookstore/gentle-introduction-to-stata/

[2]. Anil, M., (2012), Cronbach's Alpha Reliability Coefficient for Standard of Customer Services in Maharashtra State Cooperative Bank, Source: IUP Journal of Bank Management 3, p.89-95, Retrieved from http://connection.ebscohost.com/c/articles/79827821/cronbachs-alpha-reliability-coefficient-standard-customer-servicesmaharashtra-state-cooperative-bank

[3]. Babb, E. R., (2013), The Practice of Social Research. Book Thirteen Eds, Chapman University US, Retrieved from http://www.cengage.com/search/productOverview.do?Ntt=90943057215214758951950893184714305039\&N=16+4294922390+42 94922388\&Ntk=P_EPI

[4]. Baker, M. K., Simpson, K., Lloyd, B., Bauman, A. E., \& Singh, M. A. F. (2011), Behavioral strategies in diabetes prevention programs: a systematic review of randomized controlled trials, diabetes research and clinical practice, 91(1), 1-12, Retrieved from http://www.diabetesresearchclinicalpractice.com/article/S0168-8227\%2810\%2900332-3/abstract

[5]. Barnett, E., Sussman, S., Smith, C., Rohrbach, L. A., \& Spruijt-Metz, D., (2012), Motivational Interviewing for adolescent substance use: a review of the literature. Addictive behaviors, 37(12), 1325-1334, Retrieved from http://www.ncbi.nlm.nih.gov/pmc/articles/PMC3496394/

[6]. Belsky, D. W. et al., (2013), Polygenic Risk and the Developmental Progression to Heavy, Persistent Smoking and Nicotine Dependence, Evidence from a 4-Decade Longitudinal Study. JAMA Psychiatry,70(5):534-542, Retrieved from http://www.ncbi.nlm.nih.gov/pubmed/23536134

[7]. Bendassolli, P F., (2013), Theory Building in Qualitative Research: Reconsidering the Problem of Induction, Forum Qualitative Sozialforschung/Forum:Qualitative Social Research, 14(1), Art. 25, p. 50

[8]. Brown et al., (2012), A pilot study of StopAdvisor: A theory-based interactive internet-based smoking cessation intervention aimed across the social spectrum, Addictive Behaviour, 37, Retrieved from http://www.ncbi.nlm.nih.gov/pubmed/22795643

[9]. Buglow, Y., (2013), Can Mauritius become a smoking-free island, Retrieved from http://www.defimedia.info/newssunday/society/item/32877-can-mauritius-become-a-smoking-free-island.html

[10]. Campbell, S., Swinbourne, A., Cadet-James, Y., McKeown, D., \& McDermott, R. (2013), Stages of change, smoking behaviour and readiness to quit in a large sample of indigenous australians living in eight remote North Queensland communities. International journal of environmental research and public health, 10(4), 1562-1571, Retrieved from http://www.ncbi.nlm.nih.gov/pmc/articles/PMC3709334/

[11]. Caplan, L., Stout, C., \& Blumenthal, D. S., (2011), Training physicians to do office-based smoking cessation increases adherence to PHS guidelines, Journal of community health, 36(2), 238-243, Retrieved from http://www.ncbi.nlm.nih.gov/pmc/articles/PMC3668440/

[12]. Centers for Disease Control and Prevention, (2013), Smoking \& Tobacco Use, Retrieved from http://www.cdc.gov/tobacco/data_statistics/fact_sheets/cessation/quitting/

[13]. Collins, S. E., Malone, D. K., \& Larimer, M. E., (2012), Motivation to change and treatment attendance as predictors of alcohol-use outcomes among project-based Housing First residents. Addictive behaviors, 37(8), 931-939, Retrieved from http://www.ncbi.nlm.nih.gov/pubmed/22513197

[14]. Douaihya, B. A., (2013), Medications for Substance Use Disorders, Social Work in Public Health. Special Issue: The Role of Social Work in the Prevention and Treatment of Substance Use Disorders, Volume 28, Issue 3-4, pp. 264-278, Retrieved from http://www.tandfonline.com/doi/abs/10.1080/19371918.2013.759031 
[15]. Dunn K. E., Sigmon S. C., Reimann E., Badger G. J., Heil, S., Higgins, S. T., (2010), Acontingency-management intervention to promote initial smoking cessation among opioid-maintained patients, Experimental and Clinical Psychopharmacology, 18(1), pp. 37-50, Retrieved from http://www.ncbi.nlm.nih.gov/pmc/articles/PMC3605744/

[16]. Eades et al., (2012), An intensive smoking intervention for pregnant Aboriginal and Torres Strait Islander women: A randomised controlled trial, Med. J. Aust., 197, 42-46, Retrieved from http://www.ncbi.nlm.nih.gov/pubmed/22762231

[17]. Edwards, R., Russell, M., Thomson, G., Wilson, N., \& Gifford, H., (2011), Daring to dream: reactions to tobacco endgame ideas among policy-makers, media and public health practitioners, BMC public health, 11(1), 580, Retrieved from http://www.ncbi.nlm.nih.gov/pmc/articles/PMC3160990/

[18]. Eslami, A. A., Charkazi, A., Mostafavi, F., Shahnazi, H., Badeleh, M. T., \& Sharifirad, G. R., (2012), Smoking behavior, nicotine dependency, and motivation to cessation among smokers in the preparation stage of change. Journal of education and health promotion, 1-47, Retrieved from http://www.ncbi.nlm.nih.gov/pmc/articles/PMC3577406/

[19]. Finette (2013), Interview carried out in October 2013 with Dr Finette, National Methadone Centre manager at Barkly, Beau Basin Mauritius, Unpublished data, 11(3), p.89-95

[20]. Global Adult Tobacco Survey, (2014), Retrieved from, http://www.who.int/tobacco/surveillance/gats/en/

[21]. Haynes, M. J., and Smith, D. R., (2013), Tobacco use among Australian dental hygiene students is declining, but more still needs to be done, Letter to the Editor, 1-2. http://www.tobaccoinduceddiseases.com/content/11/1/22

[22]. Healthy People 2020 (2011), Retrieved from http://www.healthypeople.gov/2020/default.aspx

[23]. Heckman, C. J., Egleston, B. L., \& Hofmann, M. T., (2010), Efficacy of motivational interviewing for smoking cessation: a systematic review and meta-analysis. Tobacco control, 19(5), 410-416, Retrieved from http://www.ncbi.nlm.nih.gov/pubmed/20675688

[24]. Hung, W. T., et al., (2011), Use and perceived helpfulness of smoking cessation methods: results from a population survey of recent quitters, BMC Public Health, 11, 592, Retrieved from http://www.biomedcentral.com/1471-2458/11/592

[25]. Israel, D., (2013), Determining Sample Size, PEOD6. University of Florida. UF p1-5

[26]. ITC Project (2012), ITC Mauritius National Report-Results of the Wave 3 Survey' University of Waterloo, Ontario, Canada; Mauritius Institute of Health (MIH), Pamplemousses, Mauritius, Data retrieved from http://itc.mediadoc.com/files/ITC_Mauritius_NR_W3-Oct19v27-web.pdf

[27]. Jiloha, R. C., (2012), Tobacco smoking: How far do the legislative control measures address the problem? Indian journal of psychiatry, 54(1), 64-68, Retrieved from http://www.ncbi.nlm.nih.gov/pmc/articles/PMC3339225/

[28]. Killam, L., (2013)., Research terminology simplified: Paradigms, axiology, ontology, epistemology and methodology, Amazon Digital Services, Inc. 1-55, Retrieved from http://www.amazon.com/Research-terminology-simplified-epistemology-methodologyebook/dp/B00GLH8R9C

[29]. Kong, G., Singh, N., and Krishnan-Sarin (2012), A Review of Culturally Targeted/Tailored Tobacco Prevention and Cessation Interventions for Minority Adolescents. Oxford Journals Medicine Nicotine \& Tobacco Research, 14(12), p.1394-1406, Retrieved from http://ntr.oxfordjournals.org/content/early/2012/05/20/ntr.nts118

[30]. Lundah, Brad and Burke, Brian L., (2009), Issue Journal of Clinical Psychology, Journal of Clinical Psychology. Special Issue: Motivational Interviewing and Psychotherapy, 65(11), pp.1232-1245

[31]. Mämmelä, A., (2007), VTT Technical Research Centre of Finland 16.10.2007 1 Research methods: systems approach Research methods: systems approach Aarne Mämmel: from http://www.infotech.oulu.fi/GraduateSchool/ICourses/2007/phd_mat/lecture4-oulu-2007.pdf

[32]. Montgomery, L., Burlew, A. K., Kosinski, A. S., \& Forcehimes, A. A., (2011), Motivational enhancement therapy for African American substance users: a randomized clinical trial. Cultural Diversity and Ethnic Minority Psychology, 17(4), 357, Retrieved from http://www.ncbi.nlm.nih.gov/pmc/articles/PMC3422370/

[33]. Moore T. J., et al., (2011), Suicidal behavior and depression in smoking cessation treatments. PloS one, 6: e27016, Retrieved fromwww.plosone.org/article/info\%3Adoi\%2F10.1371\%2Fjournal.pone.0027016

[34]. Mozaffarian, D., et al., (2012), Population Approaches to Improve Diet, Physical Activity, and Smoking Habits. A Scientific Statement from the American Heart Association Circulation. 126: 1514-1563, Retrieved from http://circ.ahajournals.org/content/126/12/1514.full

[35]. Patterns and Trends of Alcohol and Other Dug Use, PATAODU. Series (2010), NATReSA, Vol 6, Republic of Mauritius

[36]. Research for International Tobacco Control (2013), WHO report on the global tobacco epidemic, World Health Organization, Retrieved from http://www.who.int/tobacco/global_report/2013/en/

[37]. Shiffman, S., (2010), Smoking-cessation treatment utilization: The need for a consumer perspective, Am J Prev Med, 38: S382-384, Retrieved from

[38]. Sofuoglu, M., et al., (2012), Galantamine attenuates some of the subjective effects of intravenous nicotine and improves performance on a Go No-Go task in abstinent cigarette smokers: a preliminary report, 224(3), pp. 413-42, Retrieved from http://www.unboundmedicine.com/medline/citation/22700039/Galantamine_attenuates_some_of_the_subjective_effects_of_intrave nous_nicotine_and_improves_performance_on_a_Go_No_Go_task_in_abstinent_cigarette_smokers:_a_preliminary_report_

[39]. Stein, M. D., Caviness, C. M., Kurth, M. E., Audet, D., Olson, J., \& Anderson, B. J., (2013), Varenicline for smoking cessation among methadone-maintained smokers: a randomized clinical trial. Drug and alcohol dependence, 133(2), 486-493, Retrieved from http://www.ncbi.nlm.nih.gov/pubmed/23953658

[40]. Stotts et al., (2010), Opioid Dependence Treatment: Options in Pharmacotherapy, Author manuscript, Expert Opinion Pharmacotheraphy ; 10(11): 1727-1740, Retrieved from

[41]. Sung, H. E., Mahoney, A. M., \& Mellow, J., (2011), Substance Abuse Treatment Gap Among Adult Parolees: Prevalence, Correlates, and Barriers, Criminal Justice Review, 36(1), pp. 40-57, Retrieved from http://cjr.sagepub.com/content/36/1/40

[42]. Winfree, W. R., Meyers, A. W. and Whelan, J. P. (2013), Validation of a Spanish translation of the Gamblers' Beliefs Questionnaire, Psychology of Addictive Behaviors, 27(1), Mar 274-278, Retrieved from http://psycnet.apa.org/journals/adb/27/1/274/ 